\title{
Jaw reflexes and masseter electromyograms in mesencephalic and pontine lesions: an electrodiagnostic study
}

\author{
B. W. ONGERBOER DE VISSER AND C. GOOR ${ }^{1}$ \\ From the Departments of Clinical Neurophysiology of the Municipal Hospital, Leyenburg, \\ The Hague and University Hospital, Leiden, The Netherlands
}

SYNOPSIS Jaw reflexes and masseter electromyograms were studied in five patients with mesencephalic and 11 patients with pontine lesions, vascular or tumorous in nature. In the former group jaw reflexes were abnormal, being delayed or absent, whereas masseter electromyograms were normal. In the latter group, both jaw reflexes and masseter EMG, showing denervation, were abnormal in six and both normal in five cases. It is suggested that the afferent limb of the human jaw reflex passes through the mesencephalic trigeminal nucleus. The methods proved to be valuable in the diagnosis of mesencephalic and pontine lesions involving the fifth cranial nerve.

Experiments in the cat have shown that unipolar cells of afferent nerve fibres from spindles of the masseter muscle are situated in the mesencephalic trigeminal nucleus (Corbin and Harrison, 1940; Szentágothaï, 1948; McIntyre, 1951; Jerge, 1962; Smith et al., 1968). Collateral branches reach the motoneurones in the pons, where they synapse to initiate the efferent side of the monosynaptic reflex arc. McIntyre and Robinson (1959) demonstrated that afferent and efferent fibres for the human jaw jerk pass through the so-called motor root. They also provided evidence indicating that in man the jaw reflex is monosynaptic. An absence of a jaw reflex response on the side of a pathological mesencephalic process was reported by Hufschmidt and Spuler (1962), but without further details. The practical usefulness of recording jaw reflexes for evaluation of the trigeminal nerve in patients with multiple sclerosis (Goodwill and O'Tuama, 1969) trigeminal neuralgia (Ongerboer de Visser and Goor, 1974), and trigeminal nerve lesions (Goor and Ongerboer de Visser, 1975) has been recognized. The purpose of the present study was to assess jaw reflex changes in relation to the

Address for correspondence: Dr C. Goor, Department of Clinical Neurophysiology, Leyenburg Hospital, The Hague, The Netherlands. (Accepted 24 August 1975.) masseter electromyographic findings in patients with midbrain lesions but without pontine involvement and the reverse. The lesions were vascular or tumorous in nature.

\section{METHODS}

Methods for studying jaw reflexes and the relevant parameters have been described elsewhere (Goodwill, 1968; Ongerboer de Visser and Goor, 1974). At the moment of tap, a microswitch in the reflex hammer triggered the sweep of a dual trace persistence oscilloscope. In the present study the right and left masseter responses were recorded simultaneously with coaxial needle electrodes, which give fewer artefacts than surface electrodes. Successive responses were superimposed with an interval of about five seconds and with the same stimulus as is used to elicit the reflex clinically.

An interval shorter than five seconds may reduce the latencies by the same amount $(0.5$ to $0.8 \mathrm{~ms})$ on each side. Superimposition of responses provides information about the variation of the reflex patterns. A data retrieval computer was used to obtain the exact time of initiation of the evoked potentials.

The latency measured from the stimulus to the beginning of the deflection of the potential forms the most useful parameter. A consistent unilateral absence, a difference of more than $0.5 \mathrm{~ms}$ between the latencies on the two sides, and a bilateral ab- 
sence of the reflex up to the age of about 70 years were considered to be pathological findings. In all patients, electromyography of the masseter muscles was performed and the current criteria for denervation-that is, fibrillation potentials and positive sharp waves-were applied.

The 16 selected patients in the present series were divided into two groups: a group (A) with midbrain lesions and a group (B) with pontine lesions. Group A comprised five cases ranging in age from 50 to 72 years. All of them showed a crossed hemiparesis with third cranial nerve involvement (Weber's syndrome). Two patients had vascular lesions and three had neoplasms verified at surgery. Group B comprised 11 cases ranging in age from 17 to 68 years. Eight of them had vascular lesions. Four showed signs and symptoms typical for pontine lesions consisting of crossed hemiparesis with involvement of sixth and seventh nerves (two cases), seventh nerve (one case), and fifth nerve (one case). In one of the eight cases, vertebral angiography revealed an occlusion of the basilar artery. In the other three, the pontine vascular lesions were verified at necropsy. The remaining three of the 11 cases had tumorous lesions. One showed angiographic findings typical for a pontine tumour and in two the diagnosis was verified at necropsy.

At the conclusion of the study all of the patients in group $\mathbf{A}$ and five of the patients in group $\mathbf{B}$ were still alive.

\section{RESULTS}

GROUP A In all five patients the jaw reflexes were abnormal-that is, unilaterally absent (Figure) in four and with an abnormal difference between the latencies $(1.2 \mathrm{~ms})$ in one. The masseter electromyograms were normal in all of these patients. The mean latency of the evoked potentials was $7.8 \mathrm{~ms}$ with a range of $6.6-8.6 \mathrm{~ms}$.

GROUP B In six patients the jaw reflexes were abnormal-that is, unilaterally absent in four and bilaterally absent in two. In four cases lacking the reflex on one side the masseter electromyograms demonstrated neurogenic abnormalities on the same side and in the two cases lacking reflexes bilaterally, denervation was found on both sides. Five of the patients had both normal jaw reflexes and normal masseter electromyograms. The mean latency of the evoked potentials was $7.8 \mathrm{~ms}$ with a range of 6.4-9.0 ms.

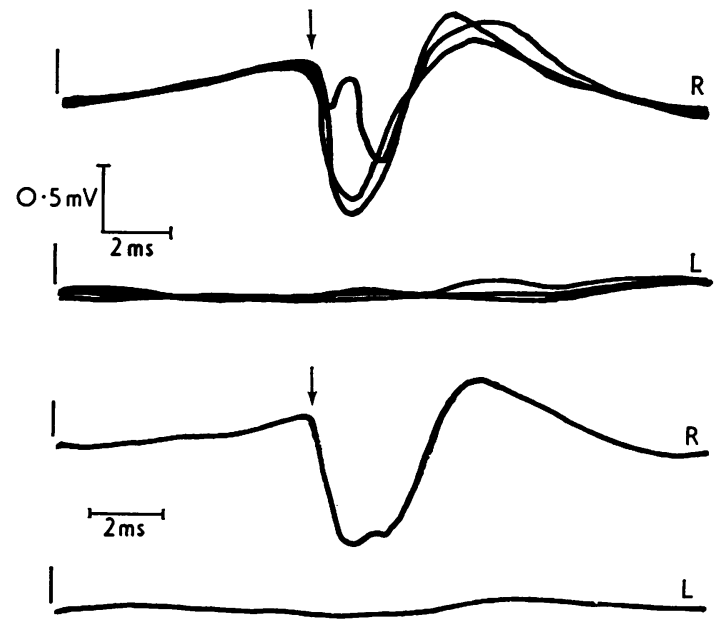

FIGURE Absent jaw reflex on the left side in a patient with Weber's syndrome. The two upper traces were made with superimposition, the lower two were obtained by averaging.

\section{DISCUSSION}

The results show clearly that registration of the jaw reflex makes it possible to detect abnormalities of this reflex that cannot be found clinically. The force of the mechanical stimulation was not standardized, because the comparison between the latencies on both sides is not affected by stimulus strength. On the basis of the anatomical data obtained in animal experiments it could be expected that, in mesencephalic lesions affecting the trigeminal nucleus, abnormal jaw reflexes would be found with normal masseter electromyograms, because most of the sensory limb of the reflex arc is located in this region. On the other hand, abnormal jaw reflexes with signs of denervation in the masseter electromyograms could be anticipated in pontine lesions affecting the trigeminal motoneurones and motor fibres. In our series with midbrain pathological processes, jaw reflexes appeared to be abnormal and masseter electromyograms normal. In six patients with pontine lesions abnormalities in the jaw reflexes and denervation potentials in the masseter electromyograms were detected. From these electrodiagnostic findings, it is reasonable to assume that the afferent limb of the human jaw reflex arc passes through the mesencephalic root of the fifth cranial nerve. Furthermore, 
recording of the jaw jerk seems to be valuable as part of the diagnostic procedure for demonstrating trigeminal nerve involvement inside the brainstem. Masseter electromyography may be helpful to determine the level involved. A noteworthy finding is that in all our cases with Weber's syndrome the fifth cranial nerve was involved, which is not mentioned in the classical neurological description. In the remaining five patients with pontine lesions, both the reflexes and the electromyograms were normal. The lesions had evidently not interrupted the pathway for the masseter reflex, but most of these patients had impaired trigeminal sensation. This may well be due to the different pathway involved. Superficial sensation is carried in the sensory trigeminal root and is transmitted centrally through the main sensory and the spinal nuclei of the trigeminal nerve. Only one patient with a vascular pontine lesion showed recovery of the jaw reflex with clinical improvement. No changes in the jaw jerk were found at the followup in the other cases.

The present study demonstrates the clinical usefulness of recording jaw reflexes in combination with electromyography of the masseter muscles in patients with structural lesions of the mesencephalon and the pons.

We wish to thank our colleagues for the referral of their patients and Dr H. A. C. Kamphuisen for his helpful comments. We are also indebted to $\mathrm{Mr} \mathrm{C}$. Schot and $\mathrm{Mr}$ D. L. J. Koster for their technical assistance and Miss T. Tjalkens for her assistance in typing.

\section{REFERENCES}

Corbin, B. K., and Harrison, F. (1940). Function of mesencephalic root of fifth nerve. Journal of Neurophysiology, 3, 423-435.

Goodwill, C. J. (1968). The normal jaw reflex: measurement of the action potential in the masseter muscles. Annals of Physical Medicine, 9, 183-188.

Goodwill, C. J., and O'Tuama, L. (1969). Electromyographic recording of the jaw reflex in multiple sclerosis. Journal of Neurology, Neurosurgery, and Psychiatry, 32, 6-10.

Goor, C., and Ongerboer de Visser, B. W. (1975). Jaw and blink reflexes in trigeminal nerve lesions: an electrodiagnostic study. Neurology (Minneap.). (In press.)

Hufschmidt, H. J., and Spuler, H. (1962). Mono- and polysynaptic reflexes of trigeminal muscles in human beings. Journal of Neurology, Neurosurgery, and Psychiatry, 25, 332-335.

Jerge, C. R. (1962). Organization and function of the trigeminal mesencephalic nucleus. Journal of Neurophysiology, 26, 379-392.

McIntyre, A. K. (1951). Afferent limb of the myotatic reflex arc. Nature, 168, 168-169.

McIntyre, A. K., and Robinson, R. G. (1959). Pathway for the jaw-jerk in man. Brain, 82, 468-474.

Ongerboer de Visser, B. W., and Goor, C. (1974). Electromyographic and reflex study in idiopathic and symptomatic trigeminal neuralgias: latency of the jaw and blink reflexes. Journal of Neurology, Neurosurgery, and Psychiatry, 37, 1225-1230.

Smith, R. D., Marcarian, H. Q., and Niemer, W. T. (1968). Direct projection from the masseteric nerve to the mesencephalic nucleus. Journal of Comparative Neurology, 133, 495-502.

Szentágothaï, J. (1948). Anatomical considerations of mono-synaptic reflex arcs. Journal of Neurophysiology, 11, 445-454. 